\title{
ANÁLISE ESPAÇO-TEMPORAL DA PRECIPITAÇÃO NO MUNICÍPIO DE CABACEIRAS NO ESTADO DA PARAÍBA
}

\section{SPACE-TEMPORAL ANALYSIS OF THE PRECIPITATION IN THE MUNICIPALITY OF CABACEIRAS IN THE STATE OF PARAÍBA}

Maxsuel Bezerra do Nascimento

Graduado em Ecologia pela Universidade Federal da Paraíba. (maxsuel10gba@hotmail.com)

Jéssica Mendes da Silva

Graduada em Ecologia pela Universidade Federal da Paraíba. (jessykasilva592@gmail.com)

Tiago Souza Clemente

Graduado em Ecologia pela Universidade Federal da Paraíba. (tiagoclemente288@gmail.com)

Lincoln Eloi de Araújo

Doutor em Recursos Naturais, Universidade Federal da Paraíba. (lincolneloi@yahoo.com.br)

\section{Resumo}

O Semiárido do Nordeste brasileiro possui irregularidade na precipitação no tempo e no espaço, e é de extrema importância compreender como essa variação influencia o meio ambiente em geral. O presente artigo tem como objetivo avaliar a variabilidade pluviométrica do município de Cabaceiras-PB, por meio da análise espaço-temporal mensal e anual da precipitação, bem como da utilização do Índice de Anomalia de Chuva (IAC), para definição dos períodos secos e chuvosos da área estudada. Os dados pluviométricos utilizados na pesquisa correspondem às séries mensais de precipitação pluviométrica, no período de 1994 a 2017, fornecidos pela AESA. A precipitação nesse município vem com maior intensidade do sentido de Oeste para Leste, visto que as chuvas que se originam do litoral não chegam nele por conta do Planalto da Borborema. Esse artigo traz uma relevância na área da ecologia, no sentido de poder contribuir, por meio dos resultados evidenciados, com a gestão municipal, através do conhecimento científico e popular, com subsídios para favorecer o meio ambiente e a atuação humana local.

Palavras-chave: Variabilidade; Períodos secos; Períodos Chuvosos.

\section{Abstract}

The semi-arid region of the Brazilian Northeast has irregular precipitation in time and space, and it is extremely important to understand how this variation influences the environment in general. The objective of this article was to evaluate the rainfall variability of the municipality of Cabaceiras-PB, through the monthly and annual spatial-temporal analysis of rainfall, and the use of the Rainfall Anomaly Index (IAC) to define dry and rainy periods studied area. The pluviometric data used in the survey correspond to the monthly series of pluviometric precipitation in the period 1994 to 2017 provided by the AESA. The precipitation of this municipality comes with greater intensity from the West to the East, since the rains that originate from the coast do not reach this municipality because of the Borborema Plateau. This article brings a relevance in the area of ecology, which through such evidences corroborate with the municipal management to the detriment of scientific and popular knowledge, with subsidies to favor the environment and local human performance.

Keywords: Variability; Dry Periods; Rainy Periods.

\section{INTRODUÇÃO}

O Semiárido do Nordeste brasileiro possui irregularidade na precipitação no tempo e no espaço, e é de extrema importância compreender como essa variação influencia o meio ambiente em geral. Deste modo, evidências científicas de que a mudança global prevê um cenário de aumento nos eventos climáticos extremos acrescentaram, à análise espacial da precipitação uma importância ainda maior devido à necessidade de compreender a grande 
variabilidade da precipitação regional intra e interanual (GAUGHAN et al., 2016).

Segundo Macedo et al. (2010), o índice pluviométrico no Estado da Paraíba depende de um conjunto de vários sistemas meteorológicos tais como: Linhas de Instabilidade; Zona de Convergência Intertropical (ZCIT); Sistemas Ondulatórios de Leste; Vórtices Ciclônicos de Altos Níveis (VCAN); Sistemas Frontais, brisas terrestre e marítima, bandas de nebulosidade; assim como efeitos orográficos locais.

Dessa forma, a Paraíba é um dos estados do Nordeste brasileiro que apresenta variabilidade espaço-temporal das chuvas considerável, sendo que Araújo et al. (2003) avaliam que a região do Cariri/Curimataú é aquela no estado com menor índice pluviométrico, com precipitações de $300 \mathrm{~mm}$ a $500 \mathrm{~mm}$, enquanto no Sertão e Alto Sertão, em torno de $700 \mathrm{~mm}$ a $900 \mathrm{~mm}$ de precipitação, no Brejo e Agreste, varia de $700 \mathrm{~mm}$ a $1.200 \mathrm{~mm}$, e o Litoral apresenta as maiores medias de precipitação, alternando entre $1.200 \mathrm{~mm}$ a $1.600 \mathrm{~mm}$.

As informações climáticas de uma determinada região são necessárias para que se possam instituir estratégias, que visem ao manejo mais adequado dos recursos naturais, planejando, dessa forma, a busca por um desenvolvimento sustentável (FRANCISCO et al., 2015). Medeiros et al. (2014) consideram que a precipitação tem essa capacidade de controlar o ciclo hidrológico e de influenciar os recursos naturais de uma bacia hidrográfica, alterando sua paisagem e, consequentemente, o meio ambiente. Assim, há a necessidade de compreender os períodos secos e chuvosos e a variabilidade espaço-temporal da precipitação do município de Cabaceiras, no intuito de estabelecer esse manejo e adequá-lo à realidade local.

Portanto, o monitoramento de períodos secos e chuvosos ou da variabilidade espaçotemporal da precipitação no Nordeste brasileiro é de extraordinária importância devido a aspectos como: a existência de numerosos planos de irrigação inseridos e a serem implantados ao longo dos principais rios; o abastecimento d'água das grandes cidades é, em sua maior parte, dependente direto do escoamento dos rios, ou indiretamente do volume acumulado nas barragens; a maior parte das culturas agrícolas depende tão-somente da regularidade das chuvas; e a possibilidade de uso de água subterrânea, que é baixa quando comparada ao da água superficial (FREITAS, 2005).

Diante do acima exposto, o presente artigo tem como objetivo avaliar a variabilidade pluviométrica do município de Cabaceiras-PB, por meio da análise espaço-temporal mensal e anual da precipitação, e da utilização do Índice de Anomalia de Chuva (IAC), para definição dos períodos secos e chuvosos da área estudada.

\section{MATERIAL E MÉTODOS}

O município de Cabaceiras (Figura 1) está localizado a 420 metros de altitude, sobre o planalto da Borborema, encontrando-se inserido na Microrregião do Cariri Oriental, que pertence a Mesorregião da Borborema, a uma distância de $180 \mathrm{~km}$ de João Pessoa, capital do Estado. Corresponde a uma área de 400,22km², representando 0,7091\% do Estado, 0,0258\% do NEB, e sua população foi estimada, em 2017, pelo Instituto Brasileiro de Geografia e Estatística (IBGE), em 5.570 habitantes, e está situado nas coordenadas geográficas latitude de $7^{\circ}$ 30'S e longitude $36^{\circ} 17^{\prime} \mathrm{W}$, com altitude média em relação ao nível do mar de 390,0 metros.

De acordo com a classificação de Köppen, que se fundamenta nos regimes térmicos e pluviométricos e na distribuição das associações vegetais, o clima de Cabaceiras é considerado do tipo As - clima quente, enquanto que segundo Thornthwaite é árido (BRASIL, 2004).

Os dados pluviométricos utilizados na pesquisa correspondem às séries mensais de precipitação pluviométrica no período de 1994 a 2017, fornecidos pela Agência Executiva de Gestão das Águas do Estado da Paraíba (AESA), sendo que, para a avaliação temporal, foram obtidos dados num posto meteorológico localizado no município de Cabaceiras (Figura 2), o qual disponibilizou uma série histórica de 24 anos, permitindo a geração de média anual da série histórica.

Para a espacialização da precipitação do Município, utilizaram-se postos meteorológicos dos municípios vizinhos, além de Cabaceiras, sendo eles: Boa Vista, Boqueirão, Barra de São Miguel, São Domingos do Cariri e São João do Cariri (Figura 3). Portanto, torna-se importante considerar esses postos circunvizinhos, pois não pode ser gerada a espacialização com apenas um posto pluviométrico, necessitando-se de três ou mais postos, sendo, no caso, considerados todos os municípios que fazem divisa territorial 
com Cabaceiras.

Assim, por meio desses valores, foi possível calcular a média mensal, ou seja, a soma da média de todos os meses dividida pelo total de meses do ano. Em seguida, criou-se uma planilha com a média acumulada e mensal de cada município, de sua média histórica de 24 anos, para poder fazer a interpolação dos dados, sendo estes depois plotados no software Surfer 8.0 para gerar a figura de espacialização do município.

Figura 1: Localização do município de Cabaceiras com relação ao Brasil e ao estado da Paraíba
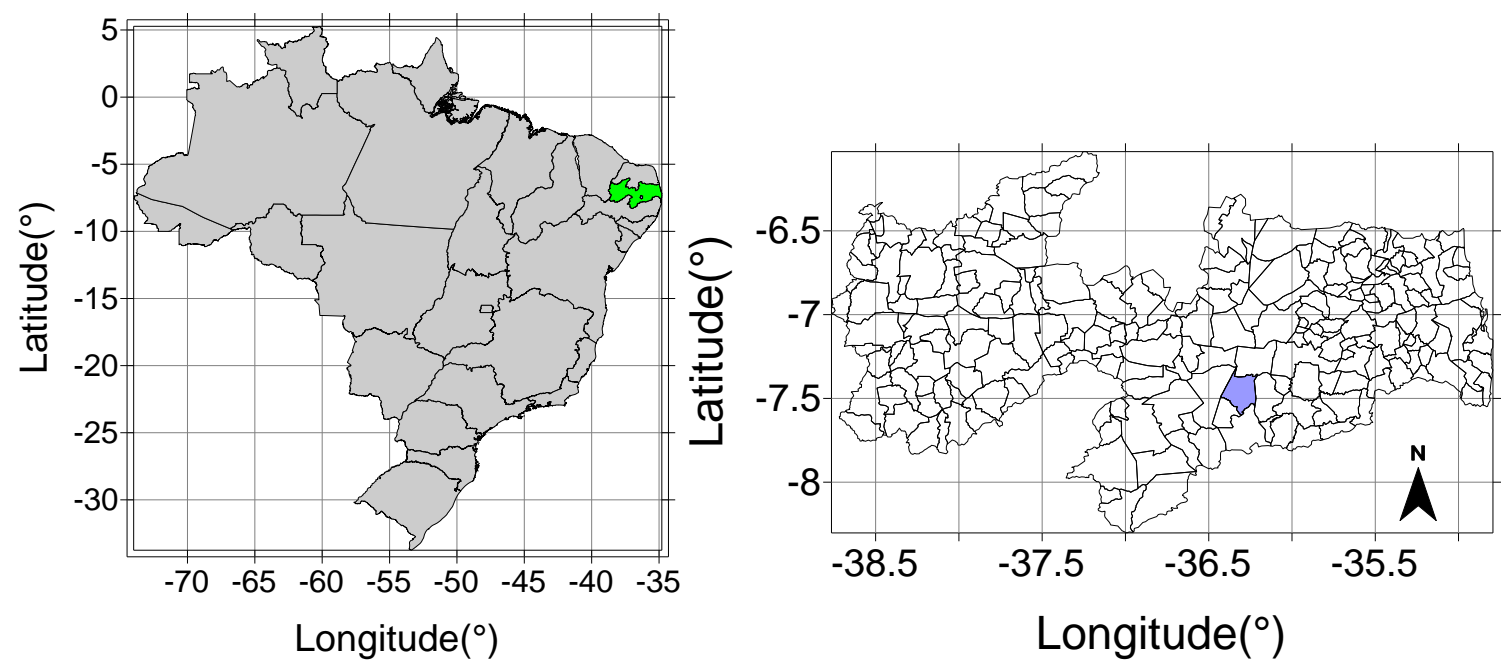

Fonte: Elaborada pelos autores.

Figura 2: Localização do ponto pluviométricos de Cabaceiras para avaliação temporal

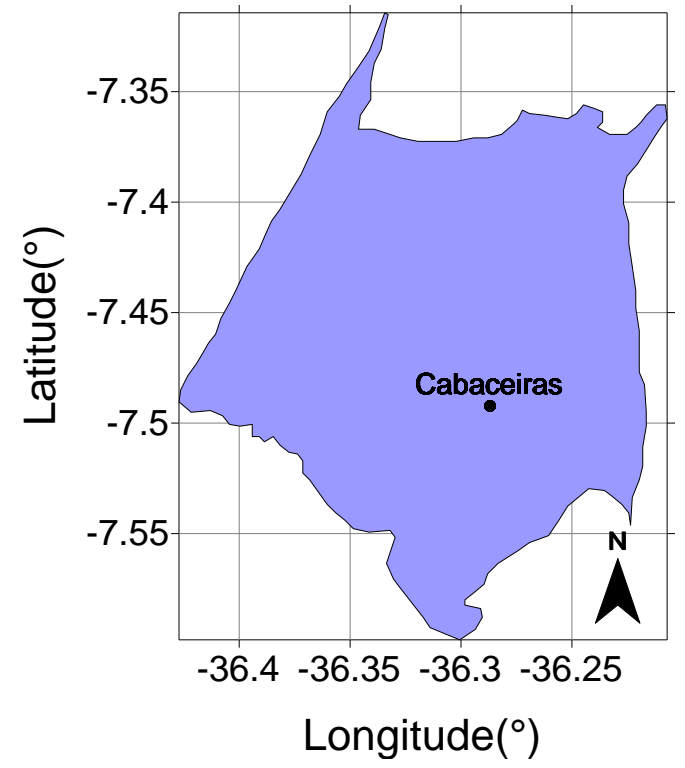

Fonte: Elaborada pelos autores.

Para análise da hipsometria (relevo) e da declividade, foram utilizadas imagens Shuttle Radar Topography Mission (SRTM) com resolução espacial de 30 metros, disponibilizadas gratuitamente pelo site TOPODATA, o qual contém os dados morfométricos do Brasil. Os referidos mapas foram analisados e espacializados por meio do software livre QGIS 2.18 .

O mapa hipsométrico foi confeccionado com base no MDT e dividido em 14 classes altimétricas, segundo o método de "quebras 
naturais" (natural breaks), em que a distribuição do conjunto de classes maximiza a diferença entre as classes e identifica pontos de quebra que melhor agrupem valores similares.
O mapa de declividade foi elaborado a partir da imagem SRTM com os valores de declividade em porcentagem. Foram estabelecidas cinco classes de declividade descritas na Tabela 1 (EMBRAPA, 1979).

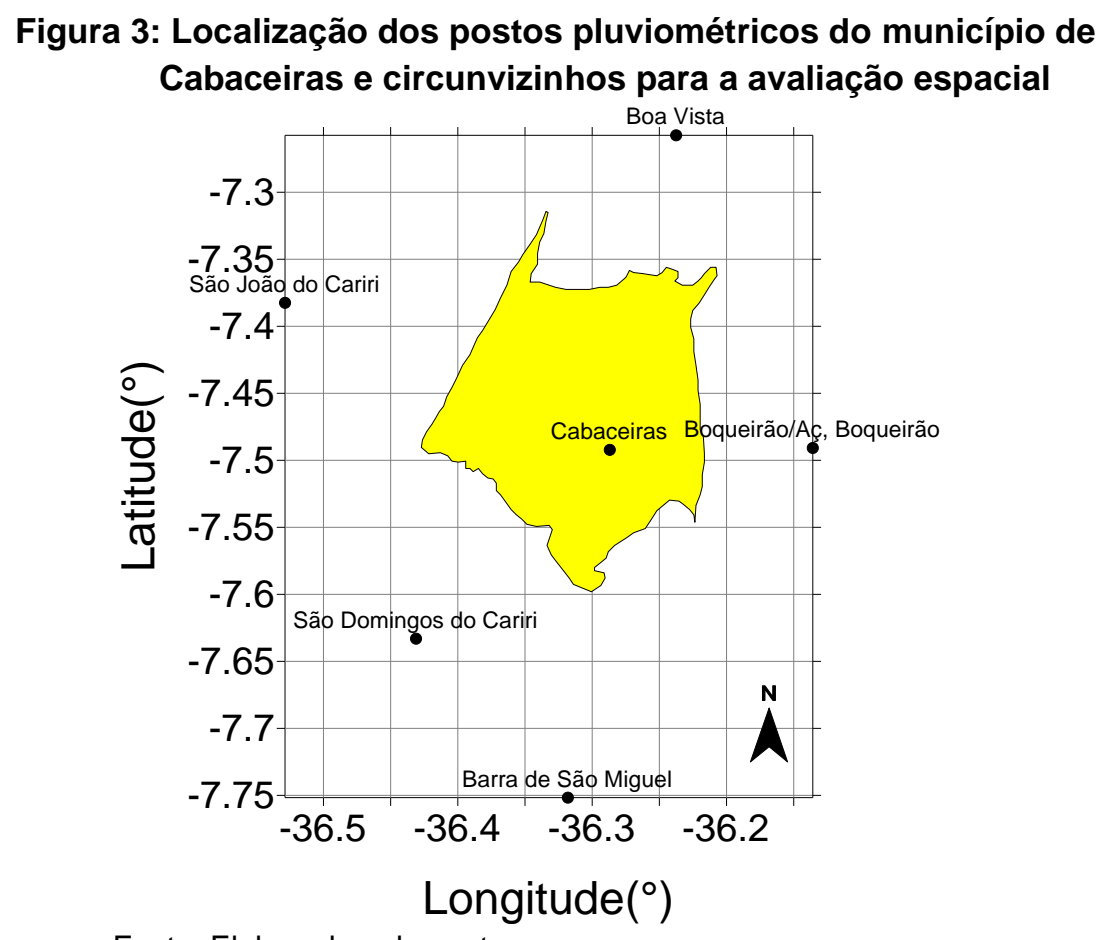

Fonte: Elaborada pelos autores.

Tabela 1: Classes de declividade em valores percentuais

\begin{tabular}{cc}
\hline Declividade (\%) & Classes \\
\hline $0-3$ & Plano \\
$3-8$ & Suave ondulado \\
$8-20$ & Ondulado \\
$20-45$ & Fortemente ondulado \\
$45-75$ & Montanhoso \\
\hline
\end{tabular}

Fonte: EMBRAPA (1979, p.27).

No intuito de gerar maior subjetividade ao trabalho, utilizou-se o IAC anual desenvolvido por Rooy (1965) e adaptado por Freitas (2004; 2005), obtido a partir das duas equações a seguir.

LAC $=3\left[\frac{(N-N)}{(\hat{M}-\mathbb{N})}\right] \quad$ Para anomalias positivas IAC $=-3\left[\frac{(N-N)}{(\tilde{X}-\mathbb{N})}\right] \quad$ Para anomalias negativas

Sendo:

$\mathrm{N}=$ precipitação mensal atual $(\mathrm{mm})$

$\bar{N}=$ precipitação média mensal da série histórica $(\mathrm{mm})$;
$\bar{M}=$ média das dez maiores precipitações mensal da série histórica $(\mathrm{mm})$;

$\bar{X}=$ média das dez menores precipitações mensais da série histórica $(\mathrm{mm})$.

Foram obtidos 7 (sete) postos pluviométricos, distribuídos nos municípios circunvizinhos ao município de Cabaceiras descritos acima, a partir da série histórica de 24 anos. Sob o ponto de vista climatológico, estas séries são consideradas bastante curtas, no entanto, de acordo com Dos Santos et al. (2011), permitem formular hipóteses sobre tendências de aumento ou redução das chuvas em condições atmosféricas extremas. 
De acordo com os mesmos autores, é recomendada uma série histórica de 30 anos de dados para se aplicar o IAC e, caso a série tenha menos do que 30 anos, recomenda-se uma adaptação em que a quantidade de médias utilizadas para se calcular o IAC seja modificada proporcionalmente à quantidade de dados disponíveis; portanto, deve-se calcular uma série de dados de 24 anos, obtendo as médias das oito maiores e das oito menores precipitações totais do período analisado. Depois de efetivado o cálculo do IAC, os valores gerados serão classificados de acordo com sua intensidade (Tabela 2).

Tabela 2: Classes de intensidades do índice de anomalia de chuva (IAC) do município de Cabaceiras-PB

\begin{tabular}{ccc}
\hline & FAIXA DO IAC & CLASSES DE INTENSIDADE \\
\hline & Acima de 4 & Extremamente úmido \\
\hline Índice & 2 a 4 & Muito úmido \\
\hline de Anomalia & 0 a 2 & Úmido \\
\hline de Chuva & 0 a -2 & Seco \\
\hline (IAC) & -2 a -4 & Muito seco \\
\hline & Abaixo de -4 & Extremamente seco
\end{tabular}

Fonte: Araújo et al. (2009).

Os resultados foram analisados $e$ classificados de acordo com a metodologia adaptada por Freitas (2005) e readaptada por Araújo et al. (2009), utilizando uma nova classificação de anos secos e úmidos.

Para compreender melhor a distribuição da precipitação entre os períodos secos e chuvosos no município de Cabaceiras, analisaram-se anos específicos da série histórica e selecionados dois anos secos e dois anos úmidos. A escolha desses anos foi devido a serem anos extremos (extremamente secos e úmidos) com relação aos demais anos da série histórica.

\section{RESULTADOS E DISCUSSÃO}

O município de Cabaceiras apresenta dois períodos distintos, um período de sete (7) meses chuvosos e outro com cinco (5) meses secos (Figura 4). O período chuvoso ocorre entre os meses de janeiro a julho, onde o mês de março é o mais representativo em termos de precipitação, no qual atinge a média de $66,5 \mathrm{~mm}$ de precipitação ocasionada por causa da atuação mais evidente da Zona de Convergência Intertropical, que atua de fevereiro a maio com uma maior precipitação nos meses de março (UVO, 1989). O período seco ocorre entre os meses de agosto a dezembro, sendo outubro destacado como o mês mais seco, com média de $5,6 \mathrm{~mm}$ de precipitação.

Vale ressaltar que o Município consta com mais meses considerados chuvosos em relação à área de estudo do que meses secos, no entanto, mesmo os chuvosos são meses de pouca representatividade, o que torna Cabaceiras um município único em suas características ambientais em relação ao clima local.

A existência de práticas e métodos para o abastecimento de água deste município é essencial, visto que o mesmo está inserido no Semiárido Nordestino, mais precisamente no Cariri Paraibano, onde é a localidade com menor pluviosidade no Estado.

Os valores acumulados da precipitação de Cabaceiras variaram de $396 \mathrm{~mm}$ a $446 \mathrm{~mm}$ (Figura 5 ), sendo que os menores valores se concentram na área Leste do município, mais especificamente nas regiões Nordeste e Sul; e os valores maiores de precipitação na região Oeste. Constata-se, assim, que a abrangência de chuvas desse município segue no sentido de Oeste para Leste por meio das chuvas oriundas, principalmente, da Zona de Convergência Intertropical que vem do Norte. As chuvas que se originam do litoral não chegam com tanta intensidade neste município por conta do Planalto da Borborema que funciona como uma espécie de barreira natural, originada do relevo da região.

Para a análise da hipsometria (Figura 6), observa-se que a área possui altitudes que variam de $363 \mathrm{~m}$ a $694 \mathrm{~m}$, cujas áreas mais baixas se encontram ao Sul, mais preciso no Sudeste com cerca de $363 \mathrm{~m}$, e as áreas mais elevadas se encontram a Oeste e Nordeste, com cerca de $694 \mathrm{~m}$. Notou-se, ainda, que a elevação de boa parte do Município fica entre $419 \mathrm{~m}$ a $465 \mathrm{~m}$. 
Figura 4: Pluviograma de precipitação mensal do município de

Cabaceiras

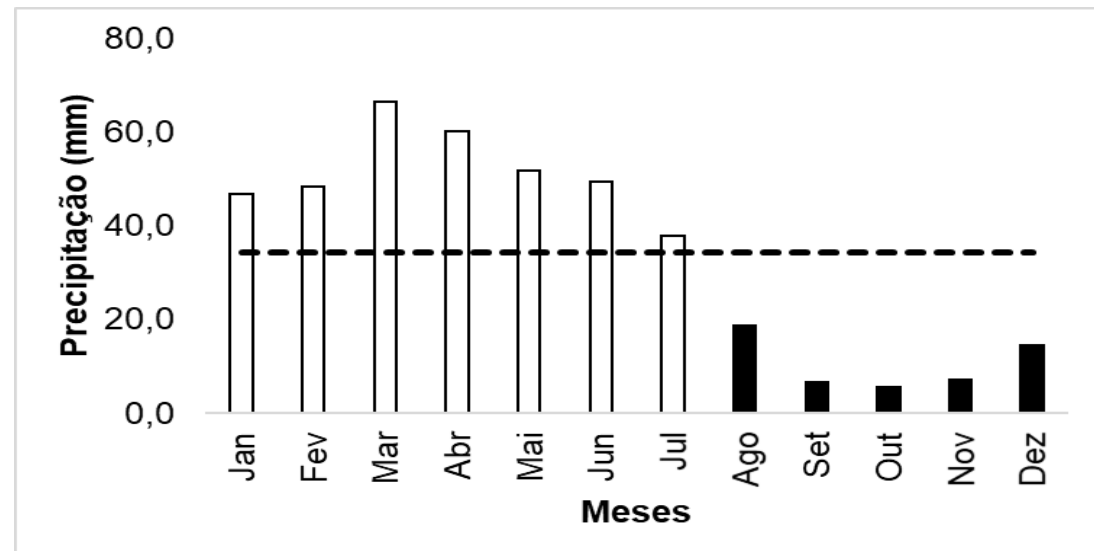

Fonte: Elaborada pelos autores.

Figura 5: Distribuição média espacial da precipitação do município de Cabaceiras

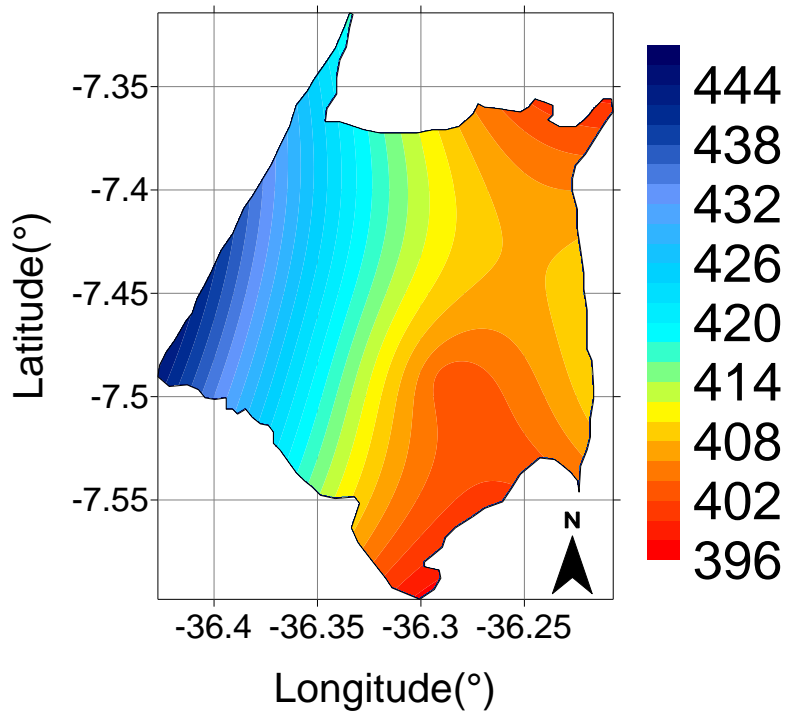

Fonte: Elaborada pelos autores.

É digno de nota que a região Leste do Município sofre influência do Planalto da Borborema, o que gera uma diminuição significativa das chuvas na região Oeste, sendo que tal precipitação ocorre devido à influência da Zona de Convergência Intertropical.

A declividade (Figura 7) caracteriza-se, predominantemente, como plano e suave ondulado, de acordo com a classificação da Embrapa (1979); já as áreas de maior declividade são representadas pela classe montanhoso, ocorrendo nas vertentes das principais serras e dos inselbergs da região.

No intuito de melhor compreender 0 comportamento dinâmico da precipitação, analisou-se a espacialização do município de
Cabaceiras mensalmente, Figura de $8(A)$ a (L). Nas Isoietas médias mensais do município de Cabaceiras, foi ilustrado o comportamento da precipitação de janeiro $(A)$ a dezembro $(L)$, em que os meses de janeiro (A) a julho (G) representam o período chuvoso do Município, cuja precipitação varia com média mensal de $50 \mathrm{~mm}$.

Já no mês de março (C) em todo o Município, há um aumento representativo na precipitação, ultrapassando os $60 \mathrm{~mm}$ em sua área Oeste. Vale destacar que o mês de março é de grande valia para o Município, devido à precipitação ser acima da média do período, no qual todo volume precipitado dá suporte, direto ou/e indiretamente, à agricultura, à fauna e à flora 
local, bem como aos mananciais, açudes e lagoas da área estudada.

Contudo, vale destacar, ainda, o mês de julho (G), mês de transição do período chuvoso para o seco da área estudada, quando acontece uma redução significativa na sua distribuição na espacialização.
Para o período seco, de agosto $(H)$ a dezembro (L), nota-se um decréscimo significativo na precipitação, como demonstra nas suas isoietas. Assim, o mês de agosto $(H)$ inicia essa diminuição com valores entre $30 \mathrm{~mm}$ a $20 \mathrm{~mm}$.

Figura 6: Hipsometria do município de Cabaceiras-PB, Brasil
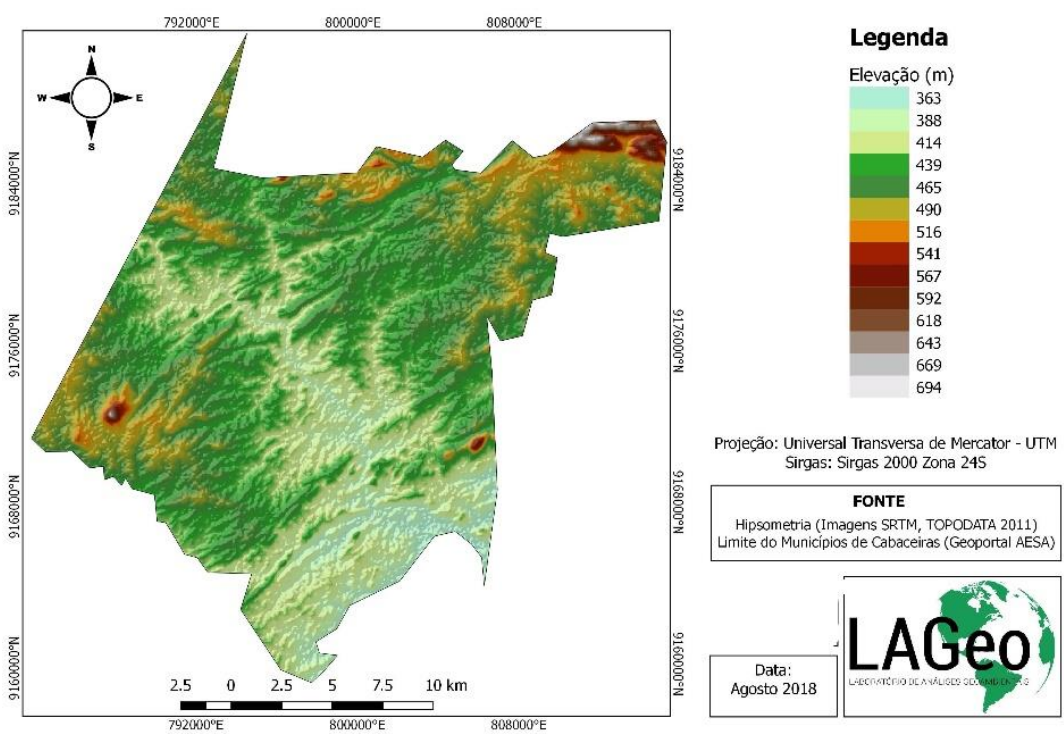

Fonte: Elaborada pelos autores.

Figura 7: Declividade do município de Cabaceiras-PB, Brasil

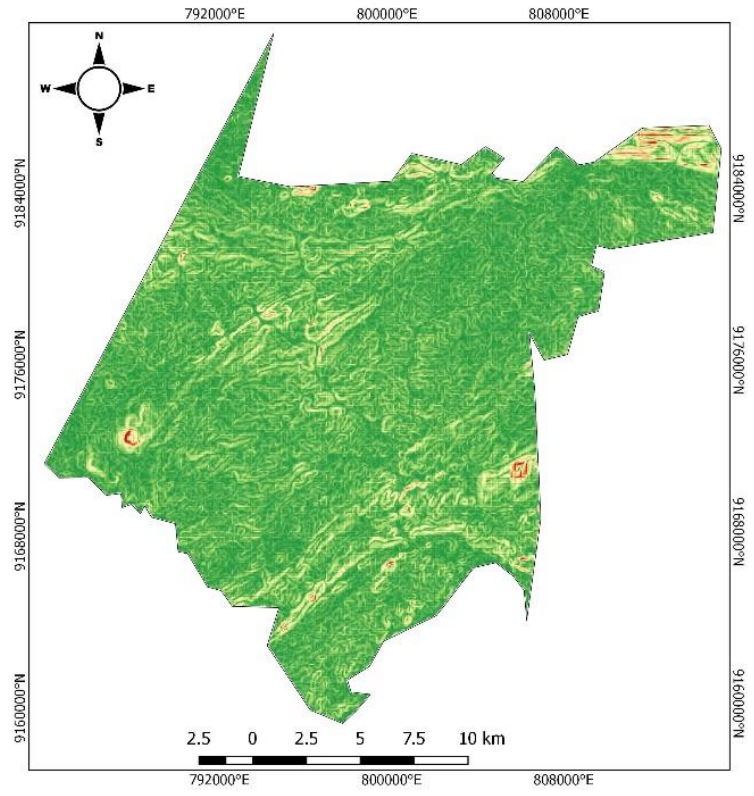

Legenda

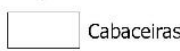

Declividade (\%)

0 a 3 (Plano)

3 a 8 (Suave Ondulado)

8 a 20 (Ondulado)

20 a 45 (Forte Ondulado)

45 a 75 (Montanhoso)

Projeção: Universal Transversa de Mercator - UTM Sirgas: Sirgas 2000 Zona $24 \mathrm{~S}$

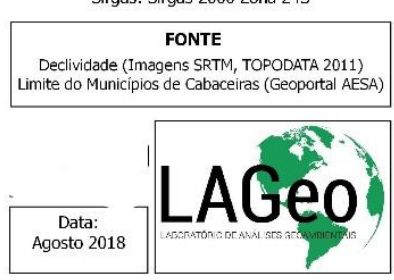

Fonte: Elaborada pelos autores.

É notório perceber que os meses de setembro (I) a novembro (K) são aqueles de menor pluviosidade do período seco, com destaque principalmente para o mês de outubro (J), em que a precipitação não passa dos $8 \mathrm{~mm}$. Diante de tais resultados, é de fundamental 
importância que, em meses como esse, o gestor municipal, junto com os proprietários de terra locais e todos os cidadãos estejam alertas à questão da água no Município e a métodos sustentáveis para a retenção deste bem e que o seu uso seja consciente e adequado ao equilíbrio ambiental, em vista do deficit de chuva nessa região.

Por fim, dezembro (L) apresentou em sua distribuição de precipitação um aumento significativo de em média $28 \mathrm{~mm}$ em boa parte do Município, em comparação aos meses anteriores do período seco. Destaca-se, ainda, que esse mês é o de transição do período seco para o chuvoso. Com a chegada mais adiante do período chuvoso, se observará um equilíbrio ambiental em benefício da fauna, flora e do homem, bem como de seus processos ecossistêmicos, permitindo a regeneração do ambiente, da água em seus mananciais e da terra.

Deste modo, Medeiros e Melo (2016) afirmam que a intensidade das chuvas é o fator mais importante, pois quanto maior a intensidade, maiores são os danos devido aos processos de erosão. Longo período de seca, seguido por outro de intensa chuva, como se caracteriza o municipio de Cabaceiras, costuma provocar expressivos prejuízos ambientais, econômicos e sociais, afetados pela variabilidade climática, como também já observaram Souza e Azevedo (2012) e Barbosa et al. (2016).

Para melhor avaliar a variabilidade da precipitação, aplicou-se o Índice de Anomalia de Chuva (IAC), o qual avalia o grau de severidade dos eventos e de duração de períodos secos e úmidos da série histórica da precipitação. De acordo com a Figura 9, a série é composta por dez anos chuvosos, que, de acordo com a Tabela 2 , foram classificados, variando entre as classes de úmido (1994,1997, 2002, 2005 e 2010), muito úmido (2008 e 2009) e extremamente úmido (2000, 2004 e 2011).

Ainda de acordo com a mesma tabela, foram encontrados catorze anos secos, classificados como seco (1995, 1996, 2001, 2003, 2006, 2007, 2013 e 2014) muito seco $(1999,2012,2015$ e 2016) e extremamente seco (1998 e 2017).

De acordo com o resultado observado sobre - IAC da série histórica do município de Cabaceiras, cabe destacar que, para os anos secos, estes podem estar associados à crise hídrica em determinadas áreas, prejudicando a agricultura e a criação de animais. Wilhite (2003) considera que todas as secas são determinadas pela ausência da precipitação, que resulta na falta de água para a sobrevivência dos seres vivos ou desenvolvimento de atividades que necessitam desse bem natural.

Outro ponto a ser destacado no IAC é que de 2012 até 2017 tal índice foi negativo, levando a um forte aumento da seca nos municípios da região, o que pode estar relacionado com a elevação da temperatura no Semiárido do Nordeste brasileiro que vem se agravando nos últimos anos.

Os anos que o IAC foi positivo dão um respaldo ao município em estudo, por este se caracterizar como o mais seco do estado da Paraíba, dando, assim, uma contribuição aos seus mananciais, à caprinocultura e maior produtividade em suas colheitas. Outro fato que contribuiu com a economia do Município foi o aumento do turismo nesses anos, principalmente 2009 e 2010.

Destaca-se ainda que, em séries grandes ou pequenas da precipitação, o importante é o entendimento da alternância de períodos chuvosos e secos, permitindo-se notar um equilíbrio ecológico entre o homem e o meio natural. O resultado desse estudo, até certo ponto, segue essa sequência, apresentando um aumento de 2008 a 2011 e uma diminuição significativa de 2012 até o presente momento.

Para melhor entender o comportamento deste índice, foi analisado o seu desempenho intra-anual, entre os anos considerados extremos, ou seja, dois anos secos e dois chuvosos, devendo ser ressaltada a sua variação dentro da estação seca e chuvosa dos anos analisados.

Os anos representados como Úmidos foram os de 2004 e 2011, tendo o IAC se mostrado positivo (Figura 10), sendo observado que 0 período chuvoso de janeiro a julho (Figura 4), no ano de 2004, ocorreu nos meses de março a maio, e no ano de 2011, no mês de junho, não seguindo a variabilidade normal do seu período, ou seja, obtendo-se o IAC negativo. Já no período seco que vai de agosto a dezembro, todos os meses seguiram sua normalidade não apresentando nenhuma anomalia.

Destaca-se ainda que, nesses anos, alguns meses obtiveram IAC negativo dentro do período chuvoso, a exemplo de 2004 que, no mês de janeiro, apresentou uma anomalia em sua precipitação bastante elevada, que o caracterizou como extremamente úmido, tendo apresentado 
também precipitação bem elevada no mês de fevereiro.

Figura 8: Isoietas médias mensais do município de Cabaceiras na Paraíba, Janeiro (A), Fevereiro (B), Março (C), Abril (B), Maio (E), Junho (F), Julho (G), Agosto (H), Setembro (I), Outubro (J), Novembro (K), Dezembro (L)
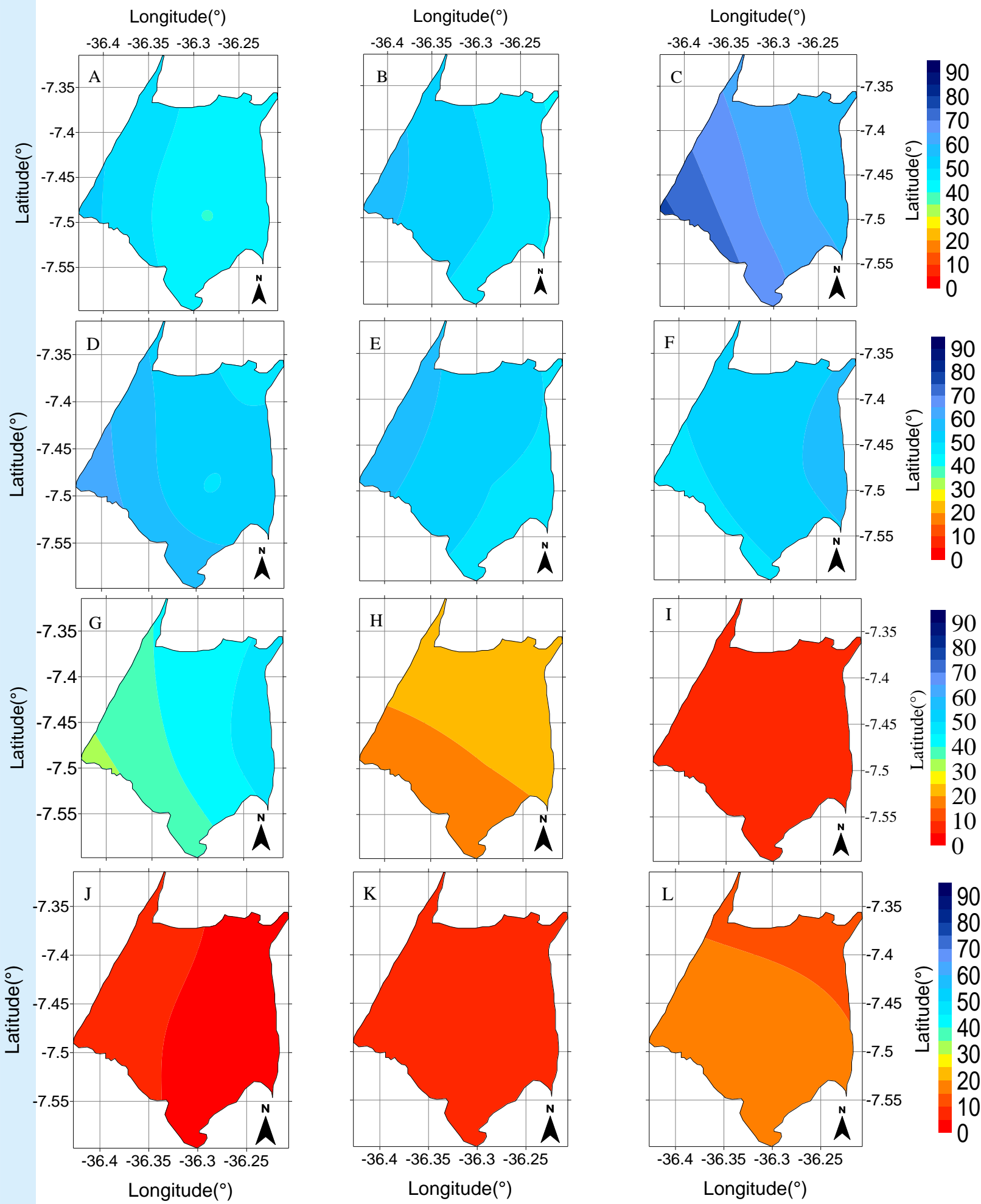

Fonte: Elaborada pelos autores. 
Figura 9: Índice de anomalia de chuva (IAC) do município de Cabaceiras-PB

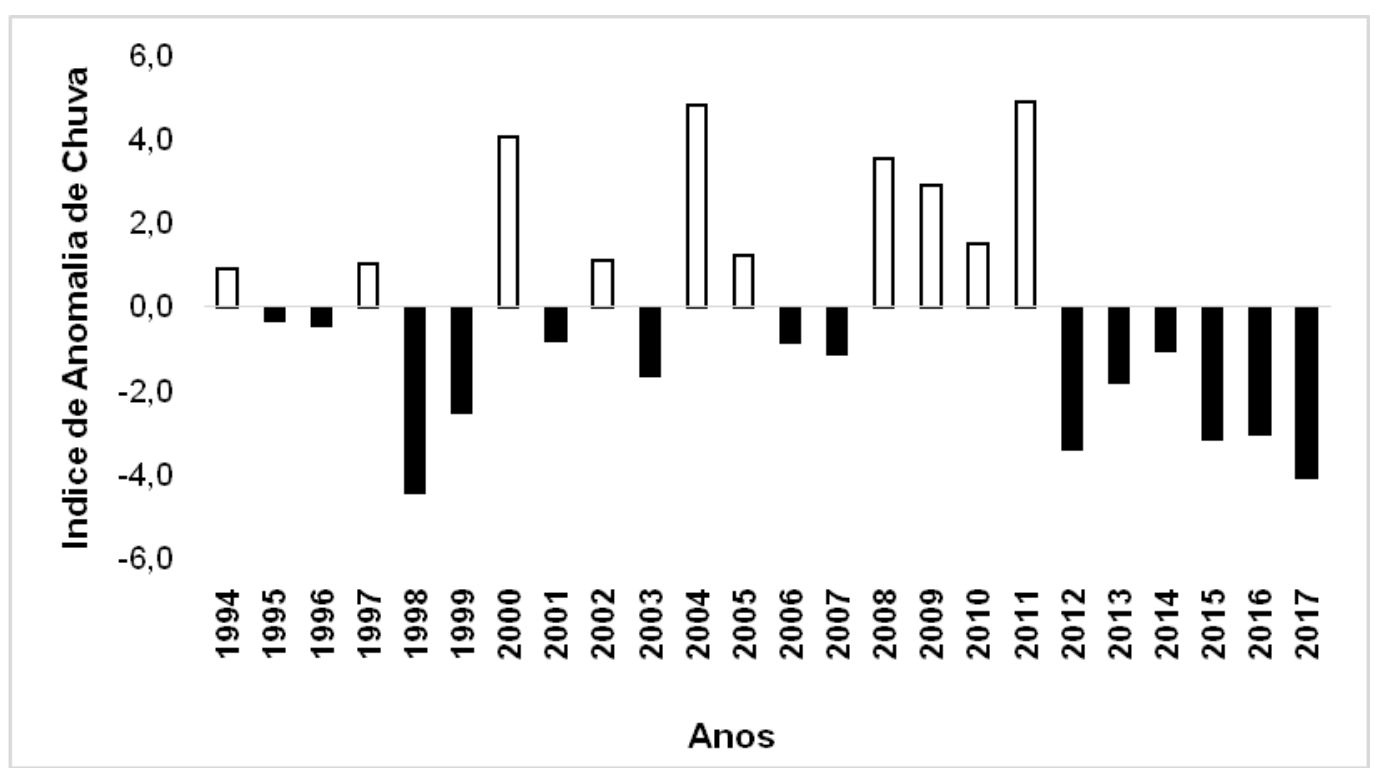

Fonte: Elaborada pelos autores.

Figura 10: IAC dos anos úmidos do município de Cabaceiras

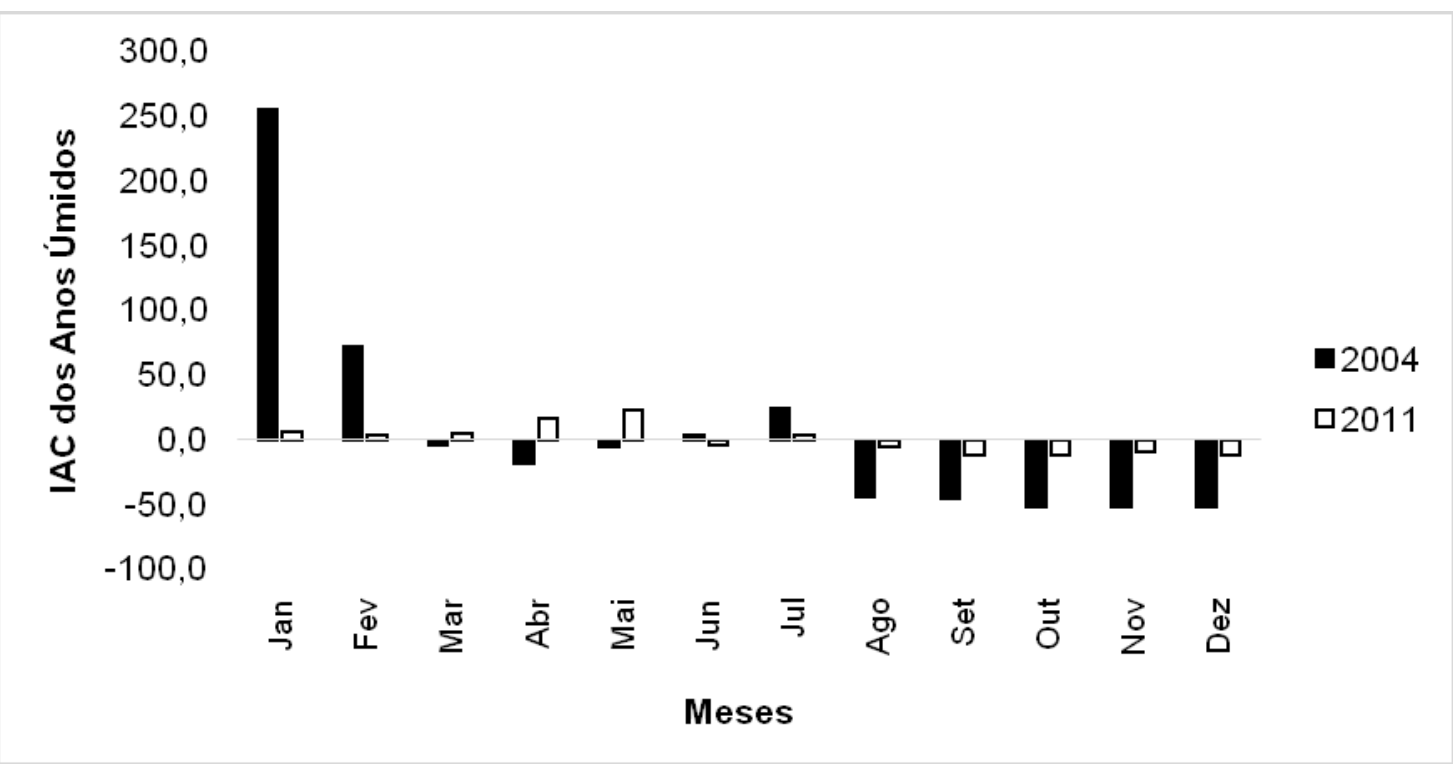

Fonte: Elaborada pelos autores.

Os anos representados como Secos foram os de 1998 e 2017, quando o IAC se mostrou negativo (Figura 11). Quanto ao período chuvoso de janeiro a julho (Figura 4), observou-se que, para o ano de 1998, os meses de janeiro e fevereiro e, para o ano de 2017, os de janeiro a março não seguiram sua variabilidade normal do período, ou seja, obteve-se o IAC negativo, corroborando com os resultados de Silva et al. (2009), que consideram que o IAC, em anos secos, tende a ser mais negativo até mesmo no período chuvoso.

Já no período seco de agosto a dezembro, o mês de agosto de 1998 apresentou uma acentuada anomalia, sendo o mês de maior precipitação, o que evidencia que, apesar desses anos serem extremamente secos, houve variabilidade na precipitação no decorrer do ano. Já no ano de 2017, todos os meses no período seco seguiram a variabilidade normal. 


\section{CONCLUSÃO}

De acordo com o presente artigo, o município de Cabaceiras-PB apresenta dois períodos, um chuvoso de janeiro a julho, no qual o mês de março é o mais representativo em níveis de precipitação, e um período seco que ocorre de agosto a dezembro, sendo outubro destacado como o mês mais seco. Salienta-se ainda que, apesar de sete meses serem considerados chuvosos, a precipitação não ultrapassa $70 \mathrm{~mm}$.

Figura 11: IAC dos anos secos do município de Areia

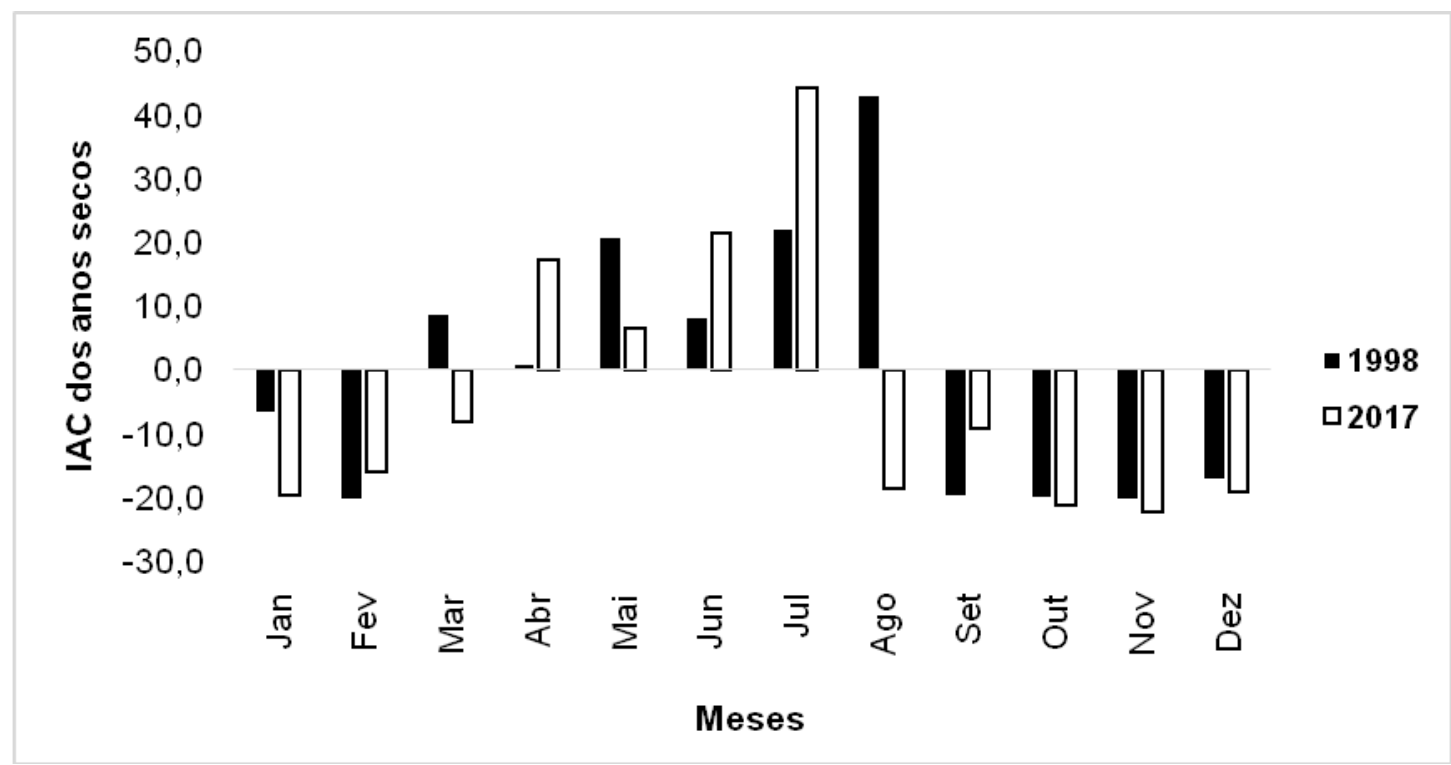

Fonte: Elaborada pelos autores.

A climatologia espacial da precipitação do município de Cabaceiras possui áreas bem distintas, cuja maior concentração de precipitação se localiza na sua região Oeste, sendo que, em contrapartida, as regiões Leste e Nordeste apresentam-se com valores baixos de precipitação.

A relação da espacialização da precipitação, em comparação com a análise do relevo, demonstrou que nesse município a região Leste sofre com a influência direta do Planalto da Borborema, e a região Oeste, com a da Zona de Convergência Intertropical.

O Índice de Anomalia de Chuva é uma ferramenta de importância significativa em todas as áreas ambientais, pois é importante para monitorar os períodos extremos (úmidos e secos), bem como para verificar 0 comportamento de uma determinada região, município e/ou bacia hidrográfica. No presente estudo, foi possível observar como a ferramenta contribuiu para tais resultados, evidenciando que durante certos anos havia alternância entre anos secos e úmidos, o que contribui com o equilíbrio ecológico, mas que nos últimos 10 anos, houve um aumento de 2007 a 2011 e uma diminuição bastante significativa de 2012 a 2017.

Por fim, é notório que este estudo apresenta relevância na área da ecologia, sendo que seus resultados podem contribuir com 0 gestor municipal, bem como com os pequenos proprietários e agricultores no sentido de dominar o conhecimento das estações apontadas, de abundância e escassez de água para as atividades antrópicas, e para estabelecer métodos de manejo a fim de suprir uma possível crise hídrica na região, com a definição dos dois períodos distintos (chuvoso e seco).

\section{AGRADECIMENTOS}

Os autores agradecem a Agência Executiva de Águas do Estado da Paraíba (AESA), pela parceria e disponibilidade dos dados para a realização da pesquisa, e ao Conselho Nacional de Desenvolvimento Científico e Tecnológico (CNPq) pela concessão da bolsa ao primeiro autor. 


\section{REFERÊNCIAS}

ARAÚJO, L. E.; BECKER, C. T.; PONTES, A. L. Periodicidade da precipitação pluviométrica no estado da Paraíba. In: CONGRESSO BRASILEIRO DE AGROMETEOROLOGIA, 13., 2003, Santa Maria. Anais... Santa Maria-RS, 2003. p. 947-948.

; MORAES NETO, J. M. DE; SOUSA, F. DE A. S. Classificação da precipitação e da quadra chuvosa da Bacia do Rio Paraíba utilizando índice de anomalia de chuva (IAC). Revista Ambi-Água, v. 4, p. 93-110, 2009.

BARBOSA, V. V.; SOUZA, W. M.; GALVÍNCIO, J. D.; COSTA, V. S. O. Análise da variabilidade climática do município de Garanhuns, Pernambuco - Brasil. Revista Brasileira de Geografia Física, v. 9, n. 2, p.353-367, 2016.

BRASIL. Ministério do Meio Ambiente. Programa de Ação Nacional de Combate à Desertificação e Mitigação dos Efeitos da Seca - PAN BRASIL. Brasília: MMA, 2004. 220p.

DOS SANTOS, E. P.; CORREIA, M. F.; ARAGÃO, M. R. S.; SILVA, F. D. S. Eventos extremos de chuva e alterações no regime hidrológico da Bacia Hidrográfica do Rio São Francisco: uma aplicação do índice RAI (Rainfall Anomaly Index). Engenharia Ambiental, v. 8, p. 315-330, 2011.

EMPRESA BRASILEIRA DE PESQUISA AGROPECUÁRIA - EMBRAPA. Serviço Nacional de Levantamento e Conservação de Solos (Rio de Janeiro, RJ). Súmula da 10. Reunião Técnica de Levantamento de Solos. Rio de Janeiro: 1979. 83p. (Embrapa-SNLCS. Micelânea, 1).

FRANCISCO, P. R. M.; MEDEIROS, R. M.; MATOS, R. M.; BANDEIRA, M. M.; SANTOS, D. Análise e mapeamento dos Índices de Umidade, Hídrico e Aridez através do BHC para o Estado da Paraíba. Revista Brasileira de Geografia Física, v. 8, n. 4, p. 1093-1108, 2015.

FREITAS, M. A. S. A Previsão de secas e a gestão hidroenergética: o caso da Bacia do Rio Parnaíba no Nordeste do Brasil. In: SEMINÁRIO INTERNACIONAL SOBRE REPRESAS Y OPERACIÓN EMBALSES, 2004, Puerto Iguazú: CACIER, v. 1. p. 1-12. 2004.
Um sistema de suporte à decisão para o monitoramento de secas meteorológicas em regiões semi-áridas. Revista Tecnologia, Fortaleza, v. suplem. p. 84-95, 2005.

GAUGHAN, A. E.; StAUB, C. G.; HOELL, A.; WEAVER, A.; WAYLEN, P. R. Inter-and intra-annual precipitation variability and associated relationships to ENSO and the IOD in southern Africa. International Journal of Climatology, v. 36 , n. 4, p. 1643-1656, 2016.

MACEDO, M. J. H.; GUEDES, R. V. S.; SOUSA, F. A. S.; DANTAS, F. R. C. Análise do índice padronizado de precipitação para o estado da Paraíba, Brasil. Revista Ambiente \& Água, v. 5, n. 1, p. 204-214, 2010.

MEDEIROS, R. B; PINTO, A. L; MIGUEL, A. E. S. Índice de anomalia de chuva (IAC) aplicado à bacia hidrográfica do Córrego Moeda, Três Lagoas/MS no período de 2011 a 2013. Fórum Ambiental da Alta Paulista, v. 10, n. 2, p. 01-16, 2014.

MEDEIROS, R. M.; MELO V. S. Estudo agroclimático do município de Cabaceiras-PB: flutuações climáticas e confusões ambientais no mecanismo da desertificação.1. ed. Campina Grande-PB: EDUFCG, 2016.

SILVA, D. F.; SOUSA F. A. S.; KAYANO M. T.; GALVÍNCIO J. D. Influência da variabilidade climática global e de suas escalas temporais sobre a precipitação no Alto Mundaú (PE). Revista Brasileira de Geografia Física, v. 2, p. 64-82, 2009.

SOUZA, W. M.; AZEVEDO, P.V. Índices de detecção de mudanças climáticas derivados da precipitação pluviométrica e das temperaturas em Recife-PE. Revista Brasileira de Geografia Física, n. 1, p. 143159, 2012.

UVO, C. R. B. A zona de convergência intertropical (ZCIT) e sua relação com a precipitação na região Norte e Nordeste brasileiro. São José dos CamposSP: USP, 1989. 99p.

WILHITE, D.A; Drought. In: HOLTON, J.A.; PYLE, C.; CURRY, J.A. (Ed.). Encyclopedia of atmospheric science. New York: Elsevier, 2003. p.650-658. 